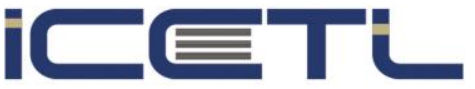

21-23 FEBRUARY, 2020

\title{
The Use Of Concept Maps in Teaching Neurology in a Physiotherapy Course
}

\author{
Hugo Santos ${ }^{1}$, Isabel Baleia² ${ }^{2}$ Elisabete Martins ${ }^{3}$ \\ ${ }^{1}$ Alcoitão School of Health Sciences
}

\begin{abstract}
A teaching and learning strategy that has recently emerged in higher education is the use of concept maps, which seems to allow the fostering of a environment of involvement of the students. The objectives of this study are to describe the use of concept maps (CM) as a teaching tool of Neurology to 2nd year Physiotherapy Students and to understand the satisfaction of these students with the elaboration of the CM and the perception of learning. Initially, an elementary $\mathrm{CM}$ about the pathophysiology of neurological diseases was created by the teachers, which was presented and explained to students. At the end of each week of classes, 3 clinical cases were provided to the students and they were asked to perform a group CM of these cases, based on the elementary $\mathrm{CM}$ and the contents covered that week. The CMs were conducted with the guidance of a 3rd grader who was trained in the structuring of the CMs. The students delivered the CM weekly and were evaluated. At the end of the course a written test was elaborated in which students had to individually elaborate a CM about 2 clinical cases. At the end of the course a questionnaire was distributed to evaluate the students' opinion about the use of CM as a teaching tool, which aimed to assess the degree of satisfaction and the perception of learning with this tool. It was feasible to organize this course based on the use of CM as a teaching tool. Of the 52 students enrolled in the course, 46 answered the questionnaire. All interviewed students (100\%) agree that the use of CM is an effective strategy in teaching these themes and that this strategy allows them to better relate the contents covered throughout the course. This study showed that concept maps can be a valid teaching strategy in the training of physiotherapists.
\end{abstract}

Keywords: active learning; mind-map; mentoring; neurology; satisfaction 